\title{
O lugar de Tenório Cavalcanti NA POLÍTICA DO RIO DE JANEIRO: UMA ANÁLISE SOBRE O ANO DE 1954
}

\author{
Claudio Araujo de Souza e Silva ${ }^{1}$
}

\begin{abstract}
Resumo
0 objetivo deste trabalho é analisar o fenômeno político expressado por Tenório Cavalcanti. Pretende-se apontar para alguns aspectos da relação estabelecida entre o ex-deputado, as suas bases eleitorais e as elites políticas existentes em seu contexto, de modo que seja possível situar o seu lugar no campo político do Rio de Janeiro. A análise se concentra sobre o ano de 1954 e coloca em questão a construção de sua identidade política, a partir de uma abordagem sobre os significados atribuídos aos conceitos de violência, udenismo e trabalhismo. A investigação empírica é baseada, sobretudo, no jornal Luta Democrática, criado por Tenório Cavalcanti. Este periódico the serviu como um importante aliado para a construção de sua imagem pública.
\end{abstract}

Palavras-chave: Tenório Cavalcanti. Violência. Udenismo. Trabalhismo.

\section{Tenório CaValcanti's Place in Rio de Janeiro's POlitics: AN ANALYSIS ABOUT THE YEAR OF 1954}

\section{Abstract}

The aim of this article is to analyze the political phenomenon expressed by Tenório Cavalcanti. It is intended to point out some aspects of the relationship between the

\footnotetext{
${ }^{1}$ Graduado em Ciências Sociais (UFRJ), Mestre em Ciência Política (IUPERJ) e Doutorando em Ciências Sociais (UERJ). claudiosouzaesilva@gmail.com
} 
former congressman, his electoral bases and the political elites within his context, so that it is possible to situate his place in the political arena of Rio de Janeiro. The study is focused on the year of 1954 and brings into question the construction of his political identity from the approach about the meanings attributed to the concepts of violence, UDN (National Democratic Union) and the labor movement. The empirical research is mainly based on the newspaper Luta Democrática, created by Tenório Cavalcanti. This journal was an important ally to construct his public image.

Keywords: Tenório Cavalcanti. Violence. UDN. Labor movement.

\section{INTRODUÇÃO}

0 ano de 1954 foi um período bastante conturbado na história política do Brasil. 0 cenário de crise se somava a um massacre de críticas ao Governo de Getúlio Vargas por parte da oposição, centrada na União Democrática Nacional (UDN). No Rio de Janeiro, capital da República, Carlos Lacerda, o principal mentor da UDN carioca, era um dos protagonistas da campanha contra Vargas, feita através do jornal Tribuna da Imprensa. 0 auge desta oposição configurou-seu no dia 5 de Agosto com o famoso atentado da Rua Tonelero, quando Lacerda responsabilizou o governo pelo ocorrido. Dezenove dias depois do atentado, Vargas se suicidou.

No dia 03 de Fevereiro deste mesmo ano, o político Natalício Tenório Cavalcanti de Albuquerque, criou o jornal Luta Democrática. Tenório Cavalcanti, assim como Carlos Lacerda, também fazia parte da ala mais radical da UDN. 0 seu jornal abriu a sede na capital da República e, logo após a fundação, foi inaugurada uma sucursal no município de Duque de Caxias. Nos meses subseqüentes, estabeleceram-se outras sucursais espalhadas por diversos municípios do Estado do Rio de Janeiro. Assim, é razoável supor que o periódico rapidamente conquistou um bom público leitor não apenas na Baixada Fluminense, mas também na capital e nos demais municípios do estado. A tiragem da Luta Democrática no seu primeiro ano de circulação era de 20 mil exemplares, metade da tiragem da Tribuna da Imprensa, que era de 40 mil exemplares. Já a Última Hora e 0 Dia, jornais maiores, tinham uma tiragem de 92 mil e 90 mil exemplares, respectivamente. 0 jornal de Tenório cresceu bastante nos anos seguintes, chegando a atingir 117 mil exemplares em 1958 e 130 mil em 1960. Deste modo, ficou atrás apenas de O Dia e $O$ Globo, os dois maiores jornais (ANUÁRIO BRASILEIRO DE IMPRENSA apud 
SIQUEIRA, 2002, p. 101). Creio que este índice da Luta Democrática em 1954 pode ser considerado alto, haja vista que era intensa a concorrência com outros grandes jornais que já circulavam há mais tempo. Além disso, Tenório Cavalcanti não foi criado no meio jornalístico assim como os políticos Chagas Freitas, de 0 Dia, e Carlos Lacerda, da Tribuna da Imprensa. No entanto, deve-se levar em consideração que a tiragem de um jornal não representa, necessariamente, o seu número de leitores e tampouco oferece uma precisão sobre a repercussão de suas notícias na opinião pública. Assim, um jornal polemista e catalisador de tensões sociais pode ser mais influente na cena política do que um outro que não adote essa mesma postura.

A Luta Democrática serviu como um baluarte para a construção da imagem pública de Tenório Cavalcanti, a promoção de suas campanhas políticas e ainda como uma forma de abrir espaço para as reivindicações sociais e políticas da população da Baixada Fluminense, tornando-se um importante meio para a consolidação política de Tenório. Nas eleições de outubro de 1954 ele ampliou a sua votação em quase de 33 mil votos e foi o deputado federal mais votado do Estado do Rio de Janeiro, afirmando-se como uma liderança popular². Carla Vieira de Siqueira (2002) observa que alguns jornais populares tiveram atuação importante durante o segundo governo Vargas, como intermediários entre o público e os líderes políticos aos quais estavam ligados. Analisando a linguagem dos jornais o Dia, Última Hora e Luta Democrática, a autora destaca que esses periódicos conseguiram estabelecer uma semântica que mesclava o sensacionalismo e a política, manejando diversos símbolos e códigos culturais.

Antes da criação de seu jornal, Tenório Cavalcanti já freqüentava os noticiários dos periódicos cariocas por causa dos inúmeros episódios relacionados à violência nos quais esteve envolvido. Nas páginas da Luta Democrática, a violência vinculada à trajetória política do ex-deputado fluminense jamais foi ocultada. Pelo contrário, o jornal procurava evidenciá-la, porém, transformava

\footnotetext{
2 Tenório Cavalcanti se elegeu deputado federal pelo Rio de Janeiro em quatro eleições consecutivas: 1950, 1954, 1958 e 1962. Na primeira eleição obteve 9.072 votos e na segunda ampliou significativamente a sua votação para 42.060 votos. Índice que pode ser considerado surpreendente para um quadro da UDN no estado do Rio de Janeiro se levarmos em consideração que a máquina político-administrativa era controlada pelo Partido Social Democrata (PSD). Neste ano de 1954 o segundo deputado mais votado da UDN, Prado Kelly, obteve um pouco mais da metade da votação de Tenório, índice similar ao de seu principal adversário político em Duque de Caxias, o ex-secretário de Segurança Pública do estado, Agenor Barcelos Feio, do PSD. (Ver: TRIBUNAL SUPERIOR ELEITORAL - TSE).
} 
o seu caráter pejorativo em valores positivos construídos por uma vivência repleta de atos de heroísmo, buscando passar a imagem de um protetor, de um homem que desafiava a morte e arriscava a sua vida, lutando contra as elites detentoras do poder, como uma forma de se sacrificar em nome do povo.

Em que pese a sua caracterização como um jornal popular e anti-elitista, o editorial da Luta Democrática pautava suas questões políticas em consonância com o discurso ideológico udenista. No entanto, parte dele destaca temas e notícias que fogem à agenda política oposicionista e se aproxima da agenda mais comumente associada ao trabalhismo de Vargas e do Partido Trabalhista Brasileiro (PTB).

A análise da Luta Democrática servirá para dar forma ao espaço que Tenório Cavalcanti ocupou no campo político do Rio de Janeiro durante o ano de 1954. Segundo Bourdieu (2010), o conceito de campo político indica que em determinadas conjunturas, que não se resumem aos períodos eleitorais, alguns políticos exercem a sua capacidade de expressar símbolos e se utilizar de instrumentos materiais que canalizam visões de mundo e demandas sociais. Estabelecem-se, assim, disputas pelo poder em que se coloca em jogo a capacidade de identificação dos políticos com o eleitorado. Essas disputas criam espaços sociais e mesmo institucionais constituídos pela dinâmica de produção e apropriação do capital político. De tal modo, as disputas travadas no campo político são sustentadas por um verdadeiro arsenal de produtos políticos, tais como: programas, discursos, análises, acontecimentos e problemas, que devem ser pesados e escolhidos pelos eleitores. 0 conceito de campo político foi utilizado por alguns autores brasileiros a fim de definir os espaços construídos na política do Rio de Janeiro.

Freire e Sarmento (2004) fazem uma síntese do que seria o campo político carioca. Os autores entendem que este campo é marcado historicamente pela convivência tensa entre dois pólos: de um lado estaria a representação da cidadecapital, com as suas questões e plataformas voltadas para o debate nacional; de outro lado, a política representada pelos interesses clientelistas, construída em torno de lideranças políticas locais, que se expressava nas áreas mais pobres e periféricas da cidade e que se relacionava com o interior do estado. Na República de 46 esta dicotomia era marcada, de um lado, por políticos cujas características principais eram o carisma, a retórica do tribuno e, sobretudo, a contestação política e a capacidade de nacionalizar os debates e, de outro lado, pelo estilo articulista e negociador de apoios e votos, que procurava evitar o combate político. 
0 primeiro padrão foi construído em torno de políticos como Carlos Lacerda e Leonel Brizola, já em relação ao outro modo de fazer política foram ícones Amaral Peixoto e Chagas Freitas.

Apesar do conceito de campo político servir como uma importante ferramenta analítica para o desenvolvimento deste trabalho, entendo que a chave composta pela diferenciação entre o nacional e o local não é suficiente para situar o fenômeno expressado por Tenório Cavalcanti na política do Rio de Janeiro, pois alguns dos principais elementos que caracterizam esse fenômeno não são evidenciados através dessa dicotomia. A maneira como foi construída a imagem pública de Tenório e de que forma esta se encaixou no campo político do Rio de Janeiro são questões centrais para esta pesquisa. Nas páginas a seguir pretendo analisar os símbolos e valores que caracterizaram o posicionamento político de Tenório Cavalcanti em um ano no qual ferviam os debates entre a situação e a oposição.

\section{A VIOLÊNCIA COMO ELEMENTO DE AFIRMAÇÃO POLÍTICA}

Tenório Cavalcanti nasceu no município de Palmeira dos Índios, interior do estado de Alagoas, em 1906. Pertencia a um ramo empobrecido de uma família que já havia possuído terras e poder no Sertão Nordestino. Após a morte de seu pai, a família se desfez de algumas propriedades e, assim, teve seus recursos de sustentação escasseados. Tenório veio para o Rio de Janeiro em 1926, em busca de melhores condições de vida. Após trabalhar em vários empregos de baixa remuneração na capital da república, foi favorecido pela notoriedade de seu padrinho, Natalício Camboim de Vasconcelos ${ }^{3}$, entre as elites políticas, haja vista que este teria contribuído para que, em 1927, Tenório fosse chamado para trabalhar como administrador da fazenda de Edgar Soares de Pinho no distrito de Duque de Caxias, que na época fazia parte do município de Nova Iguaçu. Edgar de Pinho era cunhado de Otávio Mangabeira, então ministro das Relações Exteriores no governo de Washington Luís. Na verdade, este trabalho consistia na organização de uma brigada armada, muito comum naquela época, que tinha como objetivo defender as terras de seu proprietário e combater os grupos invasores ${ }^{4}$.

\footnotetext{
${ }^{3}$ Natalício Camboim de Vasconcelos foi industrial em Alagoas e deputado federal por este mesmo estado de 1909 a 1926 (ver Fundação Getulio Vargas, 2001, p. 1292).

${ }^{4}$ Para mais informações sobre a trajetória de Tenório Cavalcanti ver: Beloch, 1986; Fortes, 1986; Fundação Getulio Vargas, 2001; Silva, 1954.
} 
A pesquisa sobre a formação sócio-econômica da Baixada Fluminense, feita por Israel Beloch, indica que a abertura da rodovia Rio-Petrópolis, inaugurada em 1928, acelerou bastante a atividade loteadora das terras marginais a esta estrada que corta o município de Duque de Caxias. Estas terras se valorizaram por estarem próximas à nova via de ligação com a cidade do Rio de Janeiro e, por isso, transformaram-se em palco de acirradas disputas, como nos narra este autor: "0 processo de aquisição e domínio dessas terras semi-abandonadas assumiu feição de verdadeira conquista pelas armas, em clima que fazia lembrar a ocupação das áreas virgens do oeste norte-americano." (BELOCH, 1986, p. 24).

0 período de disputas pelas terras valorizadas de Duque de Caxias, que compreende as décadas de 1930, 40 e 50, está associado a um enorme crescimento populacional, fruto de correntes migratórias provenientes do Nordeste, da cidade do Rio de Janeiro (onde parte das massas de trabalhadores não agüentava conviver com o elevado custo de vida) e mesmo de outras regiões da Baixada Fluminense que não experimentavam o mesmo crescimento econômico de Caxias e encontravamse decadentes.

Por um lado, este trabalho possibilitou que Tenório estabelecesse uma ampla rede de relações pessoais, constituída pelos aliados políticos de seu patrão e também pelos componentes de sua brigada armada formada, em sua maioria, por parentes e amigos vindos de sua terra natal. Por outro, não apenas posseiros, mas também agentes de polícia e delegados se tornaram os seus principais inimigos. Os constantes conflitos com as autoridades locais, principalmente aquelas vinculadas ao departamento de polícia, foram um dos motivos que levaram Tenório a deixar o cargo no início dos anos 30.

Mais tarde, fora do cargo na fazenda e já tendo acumulado algum dinheiro proveniente de um negócio ligado à venda de madeira e carvão e da valorização de terras compradas ao longo da rodovia Rio-Petrópolis, Tenório começou a ser levado por Pinho em reuniões de políticos ligados ao antigo governo de Washington Luís. Finalmente, através de contatos com o político Getúlio de Moura, filiou-se a União Progressista Fluminense (UPF). Este partido era adversário do Partido Popular Radical (PPR), chefiado por Manoel Reis, que era muito próximo a Getúlio Vargas.

Mário Grynszpan (1990) indica que a fama de Tenório como pistoleiro ágil, valente e com o corpo fechado correu por Duque de Caxias e o ajudou a tornar-se popular. Além disso, a ampla rede de relações pessoais, que incluía os laços de amizade e parentesco com as famílias mais humildes de Caxias, com as pessoas 
que fizeram parte de sua brigada e o contato com os políticos abastados, também teriam contribuído significativamente para o crescimento de sua popularidade. Estes fatores o ajudaram a se eleger, em 1936, vereador pela Câmara Municipal de Nova Iguaçu, representando o distrito de Duque de Caxias.

Em função do regime ditatorial imposto pelo Estado Novo Tenório foi destituído de seu cargo político, porém, continuou disputando espaço com as autoridades locais que apoiavam Getúlio Vargas e Amaral Peixoto. Neste período, já tendo consolidado seu nome na política caxiense, sofreu vários atentados e foi acusado de diversos crimes. 0 seu passado como inimigo público das autoridades policiais locais e a própria forma de fazer política em Caxias, cuja expressão maior se dava através da violência, foram os principais motivos dos episódios.

Após o fim do Estado Novo, quando o regime democrático voltou a vigorar no Brasil, foram criados os partidos que viriam a dominar o cenário político até 1964. Naquele momento, Tenório Cavalcanti se filiou à União Democrática Nacional (UDN). Como representante da UDN o político caxiense foi eleito deputado estadual para a Assembléia Constituinte do Rio de Janeiro em 1947. Mais tarde, como candidato nas eleições de 1950, foi eleito para a Câmara Federal, quando conseguiu a quarta votação entre os candidatos udenistas do estado. Durante a sua Legislatura, continuou dando combate cerrado a Amaral Peixoto e Getúlio Vargas.

Quando fundou o jornal Luta Democrática, em 1954, Tenório Cavalcanti ampliou a sua popularidade junto às camadas pobres da população fluminense e carioca, mas também fortaleceu os seus laços políticos com a ala mais oposicionista da UDN. No mesmo ano da criação da Luta Democrática, Tenório foi eleito o deputado federal mais votado do Estado do Rio de Janeiro5. Sem dúvida, o diário foi fundamental para fazer com que o político ganhasse projeção em todo Estado do Rio e se tornasse ainda mais popular, já que o jornal funcionava como um meio de propaganda política. Este fato se tornou ainda mais manifesto por causa do ano eleitoral.

A imagem de Tenório, como um político justiceiro que defendia os interesses do povo, foi ratificada pelo jornal que não se preocupou em esconder a relação do político com a violência. A capa preta ${ }^{6}$, que lhe conferiu a alcunha de

\footnotetext{
${ }^{5}$ Tenório Cavalcanti também foi o deputado federal mais votado do Estado do Rio de Janeiro em 1958, com 46.029 votos (ver Dicionário Histórico-Biográfico Brasileiro (FUNDAÇÃO GETÚLIO VARGAS, 2001, p. 1293).

${ }^{6}$ A vestimenta, tradicionalmente usada pelos bacharéis que se formavam em Direito em
} 
bomem da capa preta, servia para encobrir o seu principal ornamento: a famosa metralhadora chamada Lurdinha. Estes dois adereços marcaram a imagem pública de Tenório Cavalcanti e conferiram identidade a sua estética política, comumente relembrada como um ícone da violência na política da Baixada Fluminense. Esta estética era reforçada pelo jornal, que publicava diariamente a charge Vida, Paixão e Drama de Tenório, contando a cronologia, narrada em versos, dos duelos e emboscadas em que Tenório se envolveu, ressaltando que sempre que matava o fazia em legítima defesa. 0 jornal também enfatizava a imagem de Tenório como um político que teve que usar a violência para lutar pela sua liberdade e pela liberdade do povo. Um bom exemplo pode ser lido numa declaração do editor-chefe Santa Cruz Lima, que sucedeu Hugo Baldessarini, em uma reportagem sobre Tenório:

A capa preta que o cobre não representa um hábito comum ou um bom gosto. Acoberta a arma que o garante na sua integridade física. Mas que país é este em que um representante da nação tem que contar consigo próprio para poder lutar em nome daqueles que, embora humildes, são a própria seiva da nacionalidade (LIMA, 1954, p. 7).

Em sua coluna intitulada Auscultando os sofrimentos do povo, Tenório narrou algumas das respostas que deu ao público de Caxias presente em um de seus comícios:

As minhas respostas eram seguidas dos aplausos da multidão entusiasta. Uma delas se resumia no seguinte: (se o governo disse que mato, eu afirmo: feliz do povo que tem líderes capazes de matar para que não matem a liberdade do povo! Bendita é a democracia que tem seus mártires capazes de morrer, para que os inimigos do homem não acabem com o povo!) (CAVALCANTI, 1954c, p. 3).

A imagem vinculada à violência aparece, portanto, revestida pela idéia da libertação. Ou seja, a violência era necessária para livrar o povo da opressão. Tenório dizia que participava de situações que envolviam a violência porque as circunstâncias da vida política em Caxias o obrigavam a isso. 0 jornal retratava a violência como algo cotidiano na vida dos moradores de Duque de Caxias nos anos de 1950. Fora os crimes passionais, a polícia era apontada como a protagonista dos atos de violência. A instituição policial era descrita como sendo o braço armado do Governador Amaral Peixoto que, assim, conformaria uma espécie de facção.

Coimbra, foi um presente de um amigo vindo desta cidade (ver FORTES, 1986, p. 138).

O lugar de TenóRio Cavalcanti na Política do Rio de Janeiro

C. Silva $\bullet 263$ 
Tenório Cavalcanti soube usar esta atmosfera de violência a seu favor, haja vista que ela foi a base para a criação de sua imagem de político justiceiro que, ao defender a sua própria honra, protegia a dignidade do povo. A capa preta, além de ser usada para acobertar a sua metralhadora e o seu colete a prova de balas, simbolizava a sua imagem de defensor das causas populares.

Tenório Cavalcanti era, sem dúvida, uma liderança carismática, tal como é descrita por Weber $(1994,2008)$. A liderança carismática se vale da oratória e de atos de heroísmo que passam a ser vistos como exemplos de conduta. Habita o mundo das emoções e se sustenta na intersubjetividade e não na capacidade racional de que cada indivíduo é dotado para decidir o que é melhor para si mesmo. A capacidade do líder carismático em gerar bem-estar social se baseia, sobretudo, na confiança nas qualidades pessoais que é depositada na figura do líder e não na eficácia das leis ou de um conjunto de tradições. A forma de provar a legitimidade do domínio carismático, perante à população, está na percepção de que o líder é capaz de superar desafios. Na superação de desafios é que o líder carismático mostra o seu lado extraordinário e excepcional, que foge ao previsível. Os elementos simbólicos utilizados pela liderança carismática de Tenório Cavalcanti eram legitimados por se encaixarem numa espécie de cultura cívica da violência, predominante na Baixada Fluminense e nas áreas mais periféricas do Distrito Federal (ALVES, 1998). Contudo, o carisma de Tenório não se constituiu apenas com base na violência. Os símbolos e valores associados a ele também foram construídos através da forma como manejou o discurso ideológico vinculado às instituições partidárias que polarizaram o debate político na época.

\section{ENTRE O UDENISMO E O TRABALHISMO}

As colunas diárias que Tenório Cavalcanti escrevia em seu jornal Luta Democrática, assim como o editorial deste periódico, pautavam-se pela crítica ferrenha ao Governo e à figura do Presidente Getúlio Vargas. Elas eram escritas num tom que estava em consonância com o discurso de Carlos Lacerda e da Tribuna da Imprensa. No entanto, o jornal caxiense se caracterizava por adotar uma linguagem mais popular. Já, em sua primeira edição, marcava a sua posição em versos escritos pelo colunista conhecido pela alcunha de Zé Alagoano (1954, p. 1):

Alerta! Alerta Zé Povo:

Vamos ver se isto endireita! 
Foi fundada hoje esta folha,

Jornal que mete a marreta.

Ele em tudo se define: pertence a Baldessarini ${ }^{7} \mathrm{e}$ ao

homem da Capa Preta.

Tenório e Baldessarini,

A quem no momento eu louvo, fundaram este jornal

Para a defesa do povo

E dar combate cerrado

A quem for interessado

Na volta do Estado Novo.

Ao fundar o jornal, em fevereiro de 1954, é provável que Tenório Cavalcanti se sentisse obrigado a agradar os dois lados em que se apoiava a sua base política: 0 partido e o eleitorado. 0 diário alternava manchetes e colunas sobre o moralismo e o combate à corrupção na política, temas claramente vinculados a UDN, com outros temas voltados para a defesa da população mais pobre, a começar pelo seu slogan: "Um jornal de luta feito por homens que lutam pelos que não podem lutar". Na maior parte das vezes que se reportava ao público de Duque de Caxias, da Baixada Fluminense ou do Estado do Rio, as manchetes, o editorial e as colunas diárias que Tenório escrevia neste jornal abordavam temas voltados para a população de baixa renda. Este era o eleitorado do político, diversamente daquele que era mais comum aos políticos da UDN.

Segundo Maria Victoria Benevides (1981, p. 34), diversas correntes políticas, liberais e conservadoras, formaram a UDN. Apesar da diversidade, todas tinham em comum a atuação junto às camadas médias da população, sendo que os setores populares, organizados em sindicatos ou associações afins, permaneceram vinculados à política trabalhista iniciada por Vargas ou ligados aos comunistas, liderados por Prestes. Tenório não construiu sua base eleitoral junto aos setores médios da população. Seus eleitores eram oriundos das classes mais pobres.

Para Benevides (1981, p. 84), a atuação opositora e acusatória da UDN ao segundo governo Vargas, sobretudo a partir de 1952, consistiu em três grandes temas: a desgraça para o país com a volta do ex-ditador, as denúncias freqüentes de corrupção administrativa (sendo que o moralismo udenista aparecia como a marca ideológica do partido), e a necessidade de intervenção militar contra

\footnotetext{
${ }^{7}$ Hugo Baldessarini, primeiro redator-chefe da Luta Democrática, também era advogado e escrevia a coluna "Assim pensamos", que contribuía para marcar a posição anti-governista do periódico. 
a desordem social (caracterizando o golpismo e o elitismo udenista). A autora afirma que estes temas eram usualmente levantados no Congresso pela famosa "Banda de Música", grupo formado por bacharéis ligados à UDN que faziam oposição ferrenha ao governo.

A volta de Getúlio Vargas ao poder era constantemente narrada por Tenório como sendo a volta do caudilho, do ditador avesso aos preceitos democráticos, encampados pelo movimento constitucionalista de 1932, e incentivador da luta de classes e da desordem social.

Prestando uma homenagem à data referente ao movimento revolucionário de São Paulo, Tenório escreveu na coluna intitulada 0 simbólico 9 de Julho: "Tivesse São Paulo ficado cabisbaixo às afrontas que lhe foram atiradas a partir de 24 de Outubro de 1930, não teríamos conquistado a Constituição de 1934." (CAVALCANTI, 1954f, p. 3).

A lembrança da data foi descrita como uma forma de exaltar o espírito cívico da nação. Em seu livro de memórias, Tenório narrou como se a revolução paulista tivesse marcado a sua iniciação na vida política:

Corria 0 ano de 1932. A Nação navegava no mar da incerteza [...] Os novos estadistas singravam esse mar agitado e perigoso sem bússola e sem farol. Não tínhamos Constituição. As leis eram fabricadas no laboratório de uma ditadura [...] A Revolução paulista chegava até nós, na Baixada Fluminense, como badaladas plangentes de um sino, que, de quebrada em quebrada, parecia uma voz chamando o resto da Nação à luta. Surgiam em S. Paulo os famosos pistoleiros, seguindo o comando de Bertholdo Kliger, cujas tropas, já arregimentadas, marchavam com destino à capital da República. Esse movimento exercia no meu espírito uma influência impressionante. Sentia o desejo de ser paulista, de poder atravessar as linhas interditas da fronteira e também me filiar aos valentes soldados bandeirantes (SILVA, 1954, p. 45).

Continuando a narrativa, revelou em relação à Constituição de 1934:

Vencidos os paulistas, começaram, em todo o país, as movimentações partidárias para a Constituinte de 1934. Não transformei a bandeira de meus ideais em mortalha de neutralidade [...] Jamais fui político. Mas fui chegando à conclusão, lentamente, de que no mundo das coisas reais, nada poderia eu conseguir para meu país a não ser por meio da política [...] pensei muito naquela situação e resolvi aceitar um convite de Getúlio de Moura para ingressar na União Progressista Fluminense (SILVA, 1954, p. 47-48). 
A memória do movimento paulista de 1932 e da Constituição de 1934 transmite a idéia de que ao entrar para o mundo da política, Tenório já possuía uma posição ideológica contrária à Vargas. Não cabe aqui questionar a veracidade das memórias de Tenório, o que me interessa é interpretá-las como um suporte para a construção da visão de mundo do político e também tentar compreender que valores esta visão pretendia compartilhar. Para isso, é importante saber em que momento a memória foi construída e quais aspectos do contexto histórico podem dar algum sentido para que ela seja edificada de uma determinada forma. Outras fontes ${ }^{8}$ revelam que desde o início de sua carreira política Tenório se colocou em oposição a Getúlio Vargas. Suas memórias nada mais fazem do que reforçar esta tese em um momento bastante oportuno. 0 relato feito nas duas últimas citações se encaixa no discurso udenista, que procurava caracterizar Vargas como caudilho e ditador e auto proclamar-se defensora dos princípios liberais. Tenório soube utilizar estes símbolos para identificar-se com a UDN. Em suas colunas, eram muito comuns as denúncias sobre corrupção, sonegação de impostos, desvios de verbas no governo, impunidade e críticas à política econômica adotada por Vargas. Todos estes temas também constituíam a ideologia udenista.

Em relação à postura dos políticos udenistas quanto à política econômica e social do governo Vargas, Benevides afirma que:

Na realidade, toda a oposição conservadora, liderada pela UDN, alimentava suas críticas à política econômica do governo pela aversão às propostas de política social e salarial anunciadas por Getúlio (A UDN combateria os aumentos de salário mínimo em nome da estabilização, por exemplo) (BENEVIDES, 1981, p. 85).

A partir de $1^{\circ}$ de Maio, data em que Vargas anunciou a concessão de 100\% do aumento do salário mínimo, a maioria das colunas de Tenório enfatizou que a medida era demagógica e que aumentaria, em níveis alarmantes, o custo de vida. Assim, denunciou em 0 engodo do salário mínimo:

0 Sr. Getulio Vargas vem de golpear fundo a estabilidade do regimen, provocando a luta de classes, fomentando a anarquia, pregando a desordem e convulsionando a economia nacional, numa arrogante demonstração revolucionária. Ludibriou as massas trabalhistas com a ilógica elevação do salário mínimo [...] Toda a vida do país está agravada! Desde anteontem começaram a subir, demasiadamente, os custos de todas as necessidades,

${ }^{8}$ Refiro-me, basicamente, a Beloch, 1986, Fortes, 1986 e Grynszpan, 1990. 
elevação que já se acentuava continuamente há meses! Uma onda de desemprego não poderá ser impedida, tendo como resultante o enervamento das massas atiradas à miséria, advindo fatalmente a subversão da ordem (CAVALCANTI, 1954g, p. 3).

Tenório priorizou a questão do aumento do custo de vida, muito mais importante para as classes mais pobres, em relação à estabilidade do sistema financeiro. Na verdade, a atacar a política salarial do governo Vargas, Tenório não saiu da linha do discurso udenista, porém falou para um público que, em geral, ficava fora da alçada do partido de oposição. Em todo caso, disse temer o possível desencadeamento da luta de classes, uma questão bastante enfatizada pela UDN como forma de se opor à política social de Vargas.

Em outra coluna, no entanto, pareceu incitar os trabalhadores à reação. Em Extermínio dos pelegos, publicada quatro dias após a exoneração de João Goulart como Ministro do Trabalho, Tenório procurou chamar os trabalhadores a se unirem contra o sindicalismo ligado a Vargas e Goulart: "Espatifada como se encontra a politicagem tacanha que o ministro demissionário exercitava, iniciada a recuperação moral da nação, faz-se mister uma reação radical e enérgica das classes trabalhadoras, afastando de seu seio esses tartufos e torquemados". (CAVALCANTI, 1954d, p.1).

A declaração de Tenório, incitando a reação das classes trabalhadoras, poderia parecer bastante ousada para os quadros da UDN. Contudo, o que estava em jogo parecia ser mais a crítica ao governo, ao PTB, ao Ministério do Trabalho e à política sindical vinculada a eles, do que propriamente a intenção de unir a classe operária para a luta. Ainda sobre o aumento do salário mínimo, acusava em $A$ derrocada fatal:

0 povo já sabe que esse decreto foi feito menos para atender ao proletariado do que para salvar os institutos que, em insolvência, carecem de renda para cobrir as despesas eleitorais do PTB [...]. Depreende-se a gravidade da precipitada resolução, desde que não foi ela precedida do congelamento dos preços, como bem advertiam os sindicatos dos trabalhadores que estão subordinados às manobras demagógicas do Ministério do Trabalho (CAVALCANTI, 1954a, p. 3).

Se Tenório não estava interessado em estimular a luta de classes, o mesmo não se dava em relação à defesa dos direitos trabalhistas. A primeira edição do jornal reforçou a defesa desses direitos, ao publicar a manchete: A mulher 
trabalha mais de oito horas diárias! O Ministério do Trabalho estará a par das irregularidades? A reportagem subseqüente diz:

A Divisão de Higiene e Segurança do Trabalho a quem esta afeta a fiscalização do trabalho da mulher, vem de há muito permitindo que comerciantes e industriais desta Capital prorroguem o trabalho de suas empregadas e operárias por mais de oito horas diárias, dispensando a apresentação do acordo coletivo assinado entre as partes [...] e não exigindo que as mesmas sejam submetidas a exame médico, conforme determina clara e taxativamente a Consolidação das Leis do Trabalho [...] A nosso vê, tal decisão fere frontalmente a lei e se opõe aos interesses dos trabalhadores (A MULHER..., 1954, p. 6).

Esta manchete encontra-se entre a seção Justiça do Trabalho: conheça o seu direito e o artigo intitulado Sindicalismo e Previdência, em que Abstal Loureiro versou sobre o papel dos sindicatos, valorizando o seu caráter de classe e a sua relação com o Estado:

[...] o dirigente sindical torna-se desse modo valioso elemento de ligação entre os trabalhadores e os poderes públicos. Daí a conceituação de que 0 sindicato é órgão de elaboração com o Estado, seja ele de empregados ou de empregadores. Não pode o presidente ou líder sindical adotar outra conduta política senão aquela que esteja em consonância com os interesses da sua classe (A MULHER..., 1954, p. 6).

Apesar de a oposição ter explorado amplamente os anúncios de greves e problemas sociais, como forma de alardear a crise política e econômica que se desenrolou ao longo do ano de 1954, era no mínimo curioso que um discurso em defesa dos direitos trabalhistas pautasse a linha editorial de um jornal que se inseria no campo oposicionista.

Este cenário de crise serviu também para reforçar uma outra ideia bastante comum aos quadros da UDN: a intervenção militar como uma forma de manter a estabilidade das instituições democráticas. Benevides (1981, p. 86) afirma que a partir de 1953, sobretudo com a nomeação de João Goulart para o Ministério do Trabalho, a UDN e os militares representados pela Cruzada Democrática ${ }^{9}$

\footnotetext{
${ }^{9}$ A Cruzada Democrática consistiu em um movimento organizado por militares, contrários a Getúlio Vargas, que presidiu o Clube Militar entre os anos de 1952 e 1956. Durante a crise de agosto de 1954 esse grupo, juntamente com o seu braço civil concentrado na UDN, liderou uma ampla movimentação pela renúncia do presidente Vargas (ver FUNDAÇÃO GETULIO VARGAS, 2001, p. 1725).
} 
afinaram os seus discursos no combate a Vargas e ao comunismo. Tenório não poupou elogios à atuação dos militares na política nacional e principalmente ao Manifesto dos Coronéis, documento assinado por 82 coronéis e tenentes-coronéis em Fevereiro de 1954 com o intuito de protestar contra a atuação do governo, 0 descaso com as forças armadas e especificamente criticar a proposta de aumento do salário mínimo. Suas colunas destacaram o comprometimento destes militares com os poderes democráticos, taxando o governo de autoritário e chamando Vargas de o "Stalin nacional" (CAVALCANTI, 1954h, p. 3).

Com a crise de Agosto, que se agravou após o atentado contra Carlos Lacerda e que resultou na morte do major Rubens Vaz, sucederam-se as notícias afinadas com a oposição civil, concentrada na UDN, e militar, comandada pela Cruzada Democrática, a favor do impeachment de Vargas e da intervenção militar no governo. Sobre o atentado, Tenório tentou profetizar em 0 caminho da paz:

0 trevo da ditadura não vingará porque a nação sintoniza os seus anseios com as classes armadas, suportes insubstituíveis em que repousam a esperança de um povo que trabalha e paga para ser livre e viver livre dentro de uma nação livre, sob o sol fulgente da liberdade." (CAVALCANTI, 1954e, p. 3).

A comoção causada pelo suicídio de Getúlio Vargas amenizou por um tempo as críticas da oposição. No entanto, ganharam importância os debates sobre o legado deixado pelo do ex-presidente. Neste sentido, Tenório escreveu sobre os que se opunham ao governo Café Filho em A má fé dos necrófilos:

[...] os opositores são de duas categorias. Aqueles que por ignorância, longe de compreender a realidade dos fatos, alimentam a mística de que o falecido presidente Getúlio possuía dom divinatório e erigiu sozinho a legislação trabalhista, engodo de há muito desfeito com provas irrefutáveis; e os que tomaram parte do regabofe governamental, auferindo escusos proventos do regime de corrupção e degradação que passará à história como "era gregoriana." (CAVALCANTI, 1954b, p. 3).

Este desabafo, juntamente com os discursos em defesa dos direitos trabalhistas, pode ser um indício de que para construir uma identidade política popular desapegada da imagem de Vargas, Tenório não podia deixar de contemplar no seu discurso a adesão às conquistas associadas ao ex-presidente. Esta aproximação só ganha sentido na medida em que considerarmos a inserção do ex-deputado no contexto político vivenciado pelo país. Tenório era uma liderança popular sustentada pelo voto numa democracia recém-inaugurada. Sua base 
eleitoral era formada, grosso modo, pela população pobre de Caxias e dos demais municípios fluminenses, portanto, o elitismo udenista em nada lhe favorecia. Por mais que tentasse reproduzir em seu jornal os valores e o ideário do partido da oposição, não podia abrir mão de discursar para seus eleitores. Neste sentido, a defesa dos ideários trabalhistas foi manejada como uma forma de estabelecer um diálogo com essa parcela da população. Essa posição política deu margem a uma certa ambigüidade, que foi claramente expressada na observação feita por um dos auxiliares de Carlos Lacerda: "Tenório era o verdadeiro PTB dentro da UDN.” (FUNDAÇÃO GETULIO VARGAS, 2001, p. 1293). Outro exemplo de caráter dúbio é a descrição de Beloch, segundo a qual a Luta Democrática foi, com sua linguagem popular e os apelos sensacionalistas, "uma Tribuna da Imprensa dos pobres" (BELOCH, 1986, p. 100).

Ângela de Castro Gomes, baseada na leitura de Thompson, sugere pensar a incorporação da cidadania às massas trabalhadoras no Brasil atribuindo-lhe um papel de "sujeito que realiza escolbas segundo o borizonte de um campo de possibilidades" (GOMES, 2001, p. 46). A proposta analítica concebe as relações entre o Estado e a sociedade dentro de um campo de interesses comuns. Assim, a cidadania vai sendo construída de acordo com a maneira com que as classes trabalhadoras percebem e dão sentido a questões relacionadas a sua inserção no mundo, e à forma como manejam os elementos que estão ao seu dispor. Nesta mesma obra, a autora entende que o trabalhismo só pôde ser inventado num determinado momento da história brasileira, pois se valeu de aspectos anteriores que já faziam parte da vida dos trabalhadores. Assim, ao tomarem contato com uma nova estrutura legal construída pelo Estado, passaram a interpretá-la e consequentemente resignificá-la de acordo os padrões culturais que já possuíam.

Não obstante a identificação de interesses comuns entre o Estado, as classes trabalhadoras e o povo em geral, algumas lideranças populares exerceram um papel fundamental na construção do trabalhismo, pois expressaram os valores e os interesses dos atores sociais que os sustentaram em diferentes espaços sociais do país. Afinal, não teria havido apenas um trabalhismo, mas sim diversas apropriações deste conceito. A população de diferentes lugares do país e as lideranças políticas associadas a ela se conectaram através de bases semânticas próprias, muitas vezes expressadas pelos jornais e que, assim, não se limitava aos partidos políticos, às instituições estatais ou aos locais de trabalho. Não foi por acaso que Tenório Cavalcanti tentava, mesmo em sua fase udenista, manejar o 
discurso trabalhista sem se ater à figura de Vargas e do PTB. Havia espaço para isso, por mais paradoxal que uma atitude política como essa pudesse parecer.

\section{Conclusão}

A idéia deste artigo foi analisar o fenômeno político expressado por Tenório Cavalcanti, tendo como base a interpretação dos símbolos e valores implícitos na construção de sua imagem pública. 0 seu posicionamento político lhe conferiu identidade e marcou o seu o espaço no campo político do Rio de Janeiro, durante 0 ano de 1954. Em que pese o forte vínculo de Tenório Cavalcanti com a ala mais radical da UDN, procurei mostrar que o político de Caxias tentava manejar uma linguagem mais popular que se identificava com a cultura política da Baixada Fluminense e também com idéias afins ao discurso trabalhista sem se ater à figura de Vargas e do PTB.

A interpretação da linha editorial do jornal Luta Democrática durante o seu primeiro ano de circulação me serviu de base para a pesquisa. Naquele contexto político, a volta da democracia trouxe, além do forte simbolismo a ela associado, a obrigatoriedade do voto, que levou os partidos e os políticos, de todas as correntes, a buscarem o apoio popular. A relação entre os partidos, os políticos e os jornais, na tentativa de estabelecer um diálogo com um grande público, era bastante evidente na época. Além da Luta Democrática e da Tribuna da Imprensa, o jornal Última Hora, alinhado ao PTB de Vargas e O Dia, idealizado por Chagas Freitas e Adhemar de Barros, também criaram, cada um ao seu modo, uma linguagem popular em busca de reconhecimento. Este diálogo com o público através dos jornais era carregado de diversos elementos simbólicos e variados códigos culturais.

A imagem de Tenório Cavalcanti vinculada à violência foi reforçada pelo seu jornal, que ajudou a dar um caráter político à violência já existente no cotidiano caxiense. Tenório soube usar a violência da política local a seu favor, criou uma imagem de político justiceiro, aproveitou seu carisma para desenvolver sua oratória e se apresentar como um conselheiro e protetor da população. Mas, a Luta Democrática não se construiu apenas sobre a politização da violência. 0 jornal estabeleceu um diálogo com as classes pobres e trabalhadoras ao mesmo tempo em que recusava veementemente a identificação com Vargas e o PTB. Assim, Tenório Cavalcanti criou uma identidade singular e bastante representativa dentro do campo político do Rio de Janeiro. 


\section{REFERÊNCIAS}

A MULHER trabalha mais de oito horas diárias! 0 Ministério do Trabalho estará a par das irregularidades? Jornal Luta Democrática, Rio de Janeiro, 3 fev. 1954. p. 6.

ALVES, José Claudio Souza. Baixada fluminense: a violência na construção do poder. Universidade de São Paulo. 1998. Tese (Doutorado em Sociologia) Universidade de São Paulo, São Paulo.

BELOCH, Israel. Capa preta e Lurdinha: Tenório Cavalcanti e o povo da baixada. 2. ed. Rio de Janeiro: Record, 1986.

BENEVIDES, Maria Victoria de Mesquita. A UDN e o udenismo. Rio de Janeiro: Paz e Terra, 1981. (Coleção Estudos Brasileiros, 51 v.).

BOURDIEU, Pierre. A representação política: elementos para uma teoria do campo político. In: . o poder simbólico. 13. ed. Rio de Janeiro: Bertrand Brasil, 2010.

CAVALCANTI, Tenório. A derrocada fatal. Jornal Luta Democrática, 8 maio $1954 a$. p. 3 .

. A má fé dos necrófilos. Jornal Luta Democrática, Rio de Janeiro, 15 set. 1954b. p. 3 .

. Auscultando os sofrimentos do povo. Jornal Luta Democrática, Rio de Janeiro, 13 jul. 1954c. p. 3

fev. 1954d. p. 1.

. Extermínio dos pelegos. Jornal Luta Democrática, Rio de Janeiro, 26 . 0 caminho da paz. Jornal Luta Democrática, Rio de Janeiro, 14 ago 1954e. p. 3 .

. 0 simbólico 9 de julho. Jornal Luta Democrática, Rio de Janeiro, 10 jul. 1954f. p. 3.

. 0 engodo do salário mínimo. Jornal Luta Democrática, Rio de Janeiro, 5 maio 1954g. p. 3.

. Manifesto dos Coronéis. Jornal Luta Democrática, Rio de Janeiro, 7 maio 1954h, p. 3 .

FORTES, Maria do Carmo Cavalcanti. Tenório: o bomem e o mito. Rio de Janeiro: Record, 1986. 
FREIRE, Americo Oscar Guichard; SARMENTO, Carlos Eduardo Barbosa. Três faces da cidade: um estudo sobre a institucionalização e a dinâmica do campo político carioca (1889-1969). In: FREIRE, Americo Oscar Guichard; SARMENTO, Carlos Eduardo Barbosa; DA MOTTA, Marly Silva. A política carioca em quatro tempos. Rio de Janeiro: FGV, 2004.

FUNDAÇÃO GETULIO VARGAS Dicionário bistórico-biográfico brasileiro: pós1930. Rio de Janeiro: FGV, 2001. 2 v.

GOMES, Ângela de Castro. 0 populismo e as ciências sociais no Brasil: notas sobre a trajetória de um conceito. In: FERREIRA, Jorge (Org.). o populismo e sua história: debate e crítica. Rio de Janeiro: Civilização brasileira, 2001.

GRYNSZPAN, Mario. Os idiomas da patronagem: um estudo da trajetória de Tenório Cavalcanti. Revista Brasileira de Ciências Sociais, São Paulo, v. 14, 1990.

LACERDA, Carlos. Depoimento. 2. ed. Rio de Janeiro: Nova Fronteira, 1978.

LIMA, Santa Cruz. Declaração. Jornal Luta Democrática, Rio de Janeiro, 1 maio 1954. p. 7.

SILVA, Arlindo. Memórias de Tenório Cavalcanti: segundo narrativa a Arlindo Silva. Rio de Janeiro: 0 Cruzeiro, 1954.

SIQUEIRA, Carla Vieira. Sexo, crime e sindicato: sensacionalismo e populismo nos jornais Última Hora, o dia e luta democrática durante o segundo governo Vargas (1951-1954). 2002. Tese (Doutorado em História) - Pontifícia Universidade Católica do Rio de Janeiro, Rio de Janeiro.

TRIBUNAL SUPERIOR ELEITORAL - TSE. Eleitos 1945-1990. Disponível em: $<$ http://www.tse.gov.br/internet/eleicoes/eleitos1945-1990.html>. Acesso em: 15 maio 2011.

WEBER, Max. Economia e sociedade: fundamentos da sociologia compreensiva. 3. ed. Brasília: Universidade de Brasília, 1994.

Os três tipos puros de dominação legítima. In: COHN, Gabriel (Org.). Max Weber. 7. ed. São Paulo: Ática, 2008. (Coleção Grandes Cientistas Sociais, $13 \mathrm{v}$.$) .$

ZÉ ALAGOANO. Jornal Luta Democrática, Rio de Janeiro, 3 fev. 1954. p.1. 